\title{
DIVERSIDADE GENÉTICA ENTRE ACESSOS DE AÇAIZEIRO BASEADA EM MARCADORES RAPD ${ }^{(1)}$
}

\author{
Genetic diversity among accessions of assai palm based on rapd markers
}

\author{
Maria do Socorro Padilha de Oliveira², Edson Perito Amorim³ ${ }^{3}$ João Bosco dos Santos ${ }^{4}$, Daniel Furtado Ferreira ${ }^{5}$
}

\begin{abstract}
RESUMO
Caracterizou-se a diversidade genética entre acessos de açaizeiro por meio de marcadores RAPD. Foram analisados 116 acessos conservados na coleção de germoplasma da Embrapa Amazônia Oriental, Belém, PA com base em 28 primers. A matriz binária foi utilizada para a obtenção das dissimilaridades genéticas, pelo complemento artimético do coeficiente de similaridade de Dice, e também para a análise de bootstrap. As dissimilaridades genéticas foram representadas em um dendrograma gerado pelo método UPGMA. Os primers revelaram 263 bandas polimórficas e apresentaram ampla diversidade genética entre os acessos, variando de 0,06 a 0,67, sendo dois acessos de Chaves, PA, os mais divergentes. Mas, alguns acessos da mesma procedência apresentaram baixas dissimilaridades. O dendrograma permitiu a formação de oito grupos, delimitados pela dissimilaridade genética média $\left(d g_{m}: 0,40\right)$ : dois formados por um único acesso; dois constituídos por dois acessos e os demais por vários subgrupos com acessos de diferentes locais. O número ideal de bandas para a estimativa da diversidade genética entre os 116 acessos foi de 180. Logo, o número de bandas empregado neste estudo foi eficiente para caracterizar com precisão as relações genéticas entre os acessos de açaizeiro. Os acessos divergentes devem ser úteis na formação de coleções nucleares e em programas de melhoramento genético.
\end{abstract}

Termos para indexação: Euterpe oleracea, variabilidade genética, dissimilaridade, marcadores moleculares.

\section{ABSTRACT}

One characterized the genetic diversity among accessions of assai palm using RAPD markers. One hundred and sixteen accessions conserved in the Embrapa Eastern Amazon germplasm collection, in Belém, PA, were analyzed using 28 primers. The data of the binary matrix were used to estimate the genetic dissimilarities using the arithmetical complement of Dice similarity coefficient and also for the bootstrap analysis. The genetic dissimilarities were represented in a dendrogram generated by the UPGMA method. The primers revealed 263 polymorphic RAPD loci presented wide genetic diversity among the accessions, varying from 0,06 to 0,67 , being two accessions of the Chaves, PA the most divergent. But, some accessions of the same origin presented low dissimilarities. The dendrogram allowed the formation of eight groups delimited by the genetic mean dissimilarity $\left(d g_{m}: 0,40\right)$ : two formed by a single accession; two constituted by two accessions and the others for several sub-groups with accessions of different origin. The ideal number of bands for estimating the genetic diversity among 116 accessions was 180 . Therefore, the number of bands used in this study was efficient to characterize with precision the genetic relationship among the accessions of assai palm. The accessions divergent should be useful in the formation of nuclear collections and genetic breeding.

Index terms: Euterpe oleracea, genetic variability, dissimilarity, molecular markers.

(Recebido em 17 de maio de 2006 e aprovado em 24 de abril de 2007)

\section{INTRODUÇÃO}

O açaizeiro (Euterpe oleracea Mart.) é um importante recurso genético da Amazônia, explorado para atender diferentes mercados, dentre eles a obtenção da bebida açaí e a extração de palmito (OLIVEIRA et al., 2000). Nos últimos anos, o crescente mercado de frutos tem impulsionado a expansão de áreas plantas com essa palmeira, porém estudos que possam subsidiar esses plantios e implementar programas de melhoramento ainda são incipientes.
Na literatura disponível, o açaizeiro é relatado como palmeira tipicamente tropical que apresenta distribuição ampla, estando bem representada na Amazônia e que se destaca, dentre as dez espécies do genêro Euterpe nativas do Brasil, como a de maior expressão econômica (OLIVEIRA et al., 2000). Entretanto, seus centros de origem e diversidade ainda não foram estabelecidos, havendo suposições de que ocorram no estuário amazônico (CAVALCANTE, 1991; LLERAS et al., 1983; OLIVEIRA et al., 2000). Possui assincronia nas fases de floração na

\footnotetext{
${ }^{1}$ Extraído da tese de doutorado apresentada pelo primeiro autor à UFLA, Lavras. MG.

${ }^{2}$ Doutora - Laboratório de Genética/LABGEN - Embrapa Amazônia Oriental/CPATU - Travessa Dr. Enéas Pinheiro s/n - Cx.P. 48 - 66095-100 - Belém, PA spadilha@cpatu.embrapa.br

${ }^{3}$ Doutor - Pavilhão Pesquisa - Embrapa Mandioca e Fruticultura Tropical/CNPMF - Rua Embrapa s/n - Cx.P. 007 - $44380-000$ - Cruz das Almas, BA edson@cnpmf.embrapa.br

${ }^{4}$ Doutor - Departamento de Biologia/DBI - Universidade Federal de Lavras/UFLA - Cx. P. 3037 - 37200-000 - Lavras, MG - jbsantos@ufla.br

${ }^{5}$ Doutor - Departamento de Ciências Exatas/DEX - Universidade Federal de Lavras/UFLA - Cx. P. 3037 - 37200-000 - Lavras, MG - dff@ufla.br
} 
mesma inflorescência (dicogamia, do tipo protândria); tem preferência pela fecundação cruzada; e é polinizada por insetos, com a participação do vento e da gravidade na fecundação das flores. Mesmo assim, há possilibades de ocorrer autofecundação (OLIVEIRA, 2002; SOUZA, 2002).

A caracterização molecular detecta diferenças na seqüência de DNA (VICENTE et al., 2005) e quantifica a diversidade, cuja interpretação é realizada por meio de diferentes medidas de dissimilaridade, quase sempre, visualizada por métodos de agrupamento. Vários marcadores moleculares estão disponíveis para este tipo de estudo, como os marcadores RAPD (Random Amplified Polymorphic DNA), que apresentam herança dominante, utilizam primers de composição arbitrária com 10 nucleotídeos e amplificam regiões aleatórias no genoma (MILACH, 1998). Esses marcadores têm vantagens por permitir a análise de marcas polimórficas de um número ilimitado de amostras sem a influência do ambiente, em um curto espaço de tempo, utilizando pouca quantidade de DNA, além de não necessitar de informações prévias da sequiência do DNA (FERREIRA \& GRATTAPAGLIA, 1998; MILACH, 1998).

Em coleções de germoplasma de espécies perenes, os marcadores moleculares têm exercido um papel importante na quantificação da diversidade e na identificação de acessos desejáveis para programas de melhoramento genético. No Brasil, estudos dessa natureza com o emprego de marcadores RAPD têm sido registrados para algumas palmeiras perenes (RODRIGUES et al., 2004; SAWAZAKI et al., 1998; SOUSA et al., 2001). Mas, para o germoplasma de açaizeiro, há poucos relatos (COSTA et al., 2001, 2004). Assim, este trabalho teve por objetivo caracterizar a diversidade genética entre acessos de açaizeiro por meio de marcadores RAPD.

\section{MATERIAL E MÉTODOS}

Foram estudados 116 acessos conservados na coleção de germoplasma de açaí da Embrapa Amazônia Oriental, Belém, PA (1²7’21"S de latitude, 48³0'16" de longitude e $10,8 \mathrm{~m}$ de altitude). A maioria dos acessos conservados foi obtida por coletas em várias localidades do Pará, Amapá e Maranhão e registrados como Euterpe oleracea (LIMA \& COSTA, 1997), com apenas dois recebidos por intercâmbio, os híbridos interespecíficos entre Euterpe oleracea e E. espiritossantensis (OLIVEIRA et al., 2000). A procedência, assim como o local de coleta do acesso está indicada na Tabela 1 . Na coleção, cada acesso representa uma família de meio-irmãos (coleta) ou de irmãos-germanos (intercâmbio) com número variável de plantas (duas a dez plantas/acesso) e dispostas em linhas ao acaso, no espaçamento de $5 \mathrm{~m} \times 3 \mathrm{~m}$.

Folíolos da folha mais nova de todas as plantas representantes de cada acesso foram retirados, identificados, secos em estufa, embalados em sílica gel e enviados ao Laboratório de Genética Molecular do Departamento de Biologia da Universidade Federal de Lavras, MG. A extração do DNA genômico total seguiu o procedimento de Nienhuis et al. (1995) com pequenas modificações. Os DNAs dos 116 acessos empregados nas reações foram restaurados por meio da mistura equiitativa do DNA de cada planta representante do acesso nessa coleção.

A pré-seleção dos primers foi realizada pela aplicação de 120 primers RAPD em cinco acessos e os polimórficos foram aplicados em todos os acessos. $\mathrm{O}$ volume das reações foi de $16 \mu \mathrm{L}$, contendo $35 \mathrm{ng}$ da mistura de DNA genômico, $50 \mu \mathrm{M}$ de cada um dos desoxirribonucleotídeos trifosfatos (dATP, dCTP, dGTP, dTTP), 0,4 $\mu \mathrm{M}$ de primer, três unidades da enzima Taq DNA polimerase e tampão de reação $(50 \mathrm{mM}$ de Tris $\mathrm{pH}$ 8,0; 2,0mM de $\mathrm{MgCl}_{2} ; 20 \mathrm{mM}$ de $\mathrm{KCl} ; 250 \mu$ g. $\mathrm{mL}^{-1}$ de albumina de soro bovino; $1 \%$ de ficoll 400 e $1 \mathrm{mM}$ de tartrazine).

As reações foram realizadas em termociclador Mastercycler Gradiente 5331 programado para 40 ciclos e subdivididos em dois programas: 1) nos dois primeiros ciclos, foi efetuada a desnaturação do DNA a $94^{\circ} \mathrm{C}$ por dois minutos, o anelamento a $37^{\circ} \mathrm{C}$ por 15 segundos e a elongação a $72^{\circ} \mathrm{C}$ por um minuto; 2) nos demais ciclos, a diferença ocorreu apenas no tempo de desnaturação do DNA, com duração de 15 segundos. Após os 40 ciclos, ocorreu a etapa de extensão final a $72^{\circ} \mathrm{C}$ por dois minutos. A separação dos produtos amplificados foi realizada em eletroforese horizontal a $70 \mathrm{~V}$ por 3 horas e 30 minutos com gel de agarose ultrapura a $1 \%$ e corados com brometo de etídio.

Os géis foram visualizados em luz ultravioleta com o uso do equipamento Fotodyne, as imagens capturadas e arquivadas para avaliação dos padrões de bandas. Apenas as bandas nítidas foram consideradas, sendo cada banda designada como um loco genético, no qual a presença em um acesso foi representada por " 1 " e sua ausência por "0". A matriz obtida foi empregada para a estimar o número ótimo de marcadores polimórficos e a quantificação da diversidade genética.

O número ótimo de bandas foi analisado pelo método bootstrap (MANLY, 1997). Para cada par de acessos, a similaridade genética foi estimada por simulações com reamostragens de diferentes tamanhos (10, $20,30, \ldots, 240,250,260$ bandas) utilizando o software 
Tabela 1 - Identificação dos 116 acessos de açaizeiro da Coleção de Germoplasma da Embrapa Amazônia Oriental, Belém, PA.

\begin{tabular}{|c|c|c|c|}
\hline Acesso & Procedência & Local de coleta & $\mathrm{N}^{\mathrm{o}}$. de acessos \\
\hline 1 e 2 & Benfica, PA & Pomar caseiro & 02 \\
\hline 3 e 4 & Benevides, PA & Pomar caseiro & 02 \\
\hline 5 e 7 & Benevides, PA & Propriedade rural & 02 \\
\hline 6 & Mosqueiro, PA & Pomar caseiro & 01 \\
\hline $8,9,10,11$ e 12 & $\mathrm{St}^{\circ} \mathrm{Ant}^{\mathrm{o}}$ do Tauá, PA & Propriedade rural & 05 \\
\hline $\begin{array}{c}13,14,15,16,17,18,19,20,21,22 \\
23,24,25,26 \text { e } 27\end{array}$ & Chaves, PA & População natural & 15 \\
\hline $28,29,30,31,32,33,34,35,36,37$ e 38 & Muaná, PA & Propriedade rural & 11 \\
\hline $\begin{array}{c}39,40,41,42,43,44,45,46,47,48,49,50,51, \\
52,53,54,55,56,57,58,59,60,6162,63,64,6 \\
5,66,67 \text { e } 68\end{array}$ & Breves, PA & População natural & 30 \\
\hline 88 e 89 & Breves, PA & Propriedade rural & 02 \\
\hline $83,84,85,86$ e 87 & Gurupá, PA & Pomar caseiro & 05 \\
\hline 90 & Melgaço, PA & Propriedade rural & 01 \\
\hline 91 & Santarém, PA & Propriedade rural & 01 \\
\hline 93 & Santarém, PA & Pomar caseiro & 01 \\
\hline 92 & Prainha, PA & Pomar caseiro & 01 \\
\hline 109 & $\mathrm{St}^{\mathrm{a}} \mathrm{M}^{\mathrm{a}}$ do Pará, PA & População natural & 01 \\
\hline $110,111,112,113$ e 114 & Cametá, PA & População natural & 05 \\
\hline $69,70,72$ e 73 & Oiapoque, AP & População natural & 04 \\
\hline $76,78,79,80$ e 82 & Oiapoque, AP & Pomar caseiro & 05 \\
\hline $71,74,75,77$ e 81 & Macapá, AP & Pomar caseiro & 05 \\
\hline 94 & Carutapera, MA & Propriedade rural & 01 \\
\hline 95 e 96 & Maracaçumé, MA & Propriedade rural & 02 \\
\hline 97 & $\mathrm{St}^{\mathrm{a}}$ Luzia, MA & Propriedade rural & 01 \\
\hline 98 & Zé Doca, MA & Propriedade rural & 01 \\
\hline 99 e 100 & Turiaçu, MA & População natural & 02 \\
\hline 101 & $\mathrm{St}^{\mathrm{a}}$ Inêz, MA & População natural & 01 \\
\hline 102 & Cururupu, MA & Pomar caseiro & 01 \\
\hline 103 e 104 & Mirinzal, MA & População natural & 02 \\
\hline 105 e 106 & Guimarães, MA & População natural & 02 \\
\hline 107 & Alcântara, MA & População natural & 01 \\
\hline 108 & Alcântara, MA & Pomar caseiro & 01 \\
\hline 115 e 116 & Linhares, ES & Intercâmbio & 02 \\
\hline Total & - & - & 116 \\
\hline
\end{tabular}

GQMOL (CRUZ \& SCHUSTER, 2004). Nesta análise foram obtidas as estimativas de correlação de valores da matriz de similaridade, a soma de quadrados dos desvios em relação às reamostragens e o valor de estresse (E). O número de bandas polimórficas foi considerado ideal quando o estresse assumiu valor menor que 0,05 (KRUSKAL, 1964). 
As similaridades genéticas ( $\hat{s} g_{i j}$ ) entre o $i$-ésimo e o $j$-ésimo acesso foram estimadas com o emprego do coeficiente de similaridade de Dice (REIF et al., 2005) pelo software NTSYS-pc 2,1 (ROHLF, 2000). A análise de agrupamento foi realizada com base na matriz das estimativas de dissimilaridades, obtida a partir do complemento aritmético do coeficiente de similaridade $\left(\mathrm{dg}_{\mathrm{ij}}=1-\hat{\mathrm{s}} \mathrm{g}_{\mathrm{ij}}\right)$, com o emprego de método da média não ponderada das dissimilaridades-UPGMA (Unweighted pair-group method averages). $\mathrm{O}$ dendrograma foi gerado com base na matriz genética no procedimento SAHN do software NTSYS-pc 2,1 (ROHLF, 2000). No dendrograma os grupos formados pelos acessos foram separados a partir do ponto de corte feito com base na estimativa do complemento aritmético médio $\left(\mathrm{dg}_{\mathrm{m}}\right)$, obtido pela expressão:

$$
\mathrm{dg}_{\mathrm{m}}=\sum \mathrm{dg}_{\mathrm{ij}} / \mathrm{N}
$$

em que:

$d g_{i j}$ : complemento aritmético entre cada par; $\mathrm{N}$ : número de pares obtidos.

Analisou-se também, a consistência de cada agrupamento por meio do teste $\mathrm{Z}$ de Mantel no software NTSYS-pc 2,1 (ROHLF, 2000).

\section{RESULTADOS E DISCUSSÃO}

Encontram-se listados na Tabela 2, os 28 primers selecionados. Estes primers geraram 263 produtos de amplificação, sendo $100 \%$ polimórficos e com média de 9,4 bandas por primer. O primer OPM-04 que amplificou o maior número de bandas, enquanto o menor número ocorreu no primer OPB-01. Sawazaki et al. (1998) obtiveram número semelhante de marcadores RAPD (265), sendo $96 \%$ polimórficas, quando analisaram nove ecotipos com e sem perfilhamento do gênero Euterpe. Porém, Costa et al. (2001, 2004) encontraram número bem inferior de bandas polimórficas (177 e 161) em dez indivíduos de diferentes procedências e quinze indivíduos com variação para perfilhamento e coloração dos frutos, respectivamente.

Resultados similares também foram constatados na pupunheira, uma palmeira perene e monóica (RODRIGUES et al., 2004; SOUSA et al., 2001). Contudo, em caiaué, palmeira nativa da Amazônia, Moretzsohn et al. (2002) encontraram níveis de polimorfismo bem inferiores ao analisarem 175 acessos, produzindo média de três bandas por primer. Em germoplasma de outras espécies arbóreas tropicais, também foi registrado alto nível de polimorfismo com o uso desse marcador (FALEIRO et al., 2001; MARQUES et al., 2002; YAMADA et al., 2002). Tais resultados permitem sugerir que há uma tendência do germoplasma dessas plantas, especialmente daquelas pouco melhoradas em apresentarem alto polimorfismo. $\mathrm{O}$ elevado polimorfismo detectado nos acessos aqui estudados pode estar relacionado ao fato dessa espécie ser monóica, preferencialmente alógama e encontrar-se em fase de domesticação. Conseqüentemente, seu germoplasma deve ter sofrido baixa pressão de seleção, o que pode garantir ganhos genéticos significativos com a seleção. Vale ressaltar ainda que a maioria dos acessos analisados são oriundos do segundo centro de diversidade genética do gênero Euterpe (LLERAS et al., 1983), onde possivelmente, deva estar inserido o centro de diversidade do açaizeiro. Tais inferências justificam a ampla diversidade genética detectada entre os acessos aqui estudados.

As análises de reamostragens (bootstrap) encontram-se resumidas na Figura 1. Observa-se que houve uma relação direta entre o número de bandas analisadas e a magnitude de correlação dos valores da matriz de similaridade original obtida a partir de reamostragens com diferentes números de bandas, com consistência a partir de 180 bandas, quando a correlação atingiu 0,96 e valor de estresse de 0,046 (KRUSKAL, 1964). Para Colombo et al. (2000), intervalo entre 50 a 100 bandas é considerado suficiente para estimar relações genéticas entre e dentro de espécies vegetais. Como neste estudo, o número ideal de bandas encontrado foi bem acima deste intervalo, além dos cálculos das diversidades terem sido realizados com base nas 263 bandas polimórficas geradas $(r=0,999$ e $\mathrm{E}=0,01$ ), pode-se inferir que as estimativas da diversidade genética entre os acessos estudados apresentam excelente precisão.

As dissimilaridades entre os acessos variaram de 0,06 a 0,67 com média de 0,40 . Os menores valores foram registrados entre os acessos 102 e 103 coletados em duas localidades do Maranhão geograficamente próximas, Cururupu e Mirinzal, mas em condições distintas, pomar caseiro e população natural, respectivamente. Por outro lado, os acessos 14 e 22 foram os mais distantes geneticamente, ambos coletados na mesma população natural de Chaves, PA. Um outro aspecto a ser enfatizado é que quase a metade dos acessos $(43,97 \%)$ demonstrou dissimilaridades médias iguais ou acima da média geral, com possibilidades de alta diversidade genética nos acessos. Estes resultados corroboram com os obtidos por Costa et al. (2001, 2004), quando analisaram dez e quinze indivíduos da coleção de germoplasma aqui estudada, de diferentes localidades e com variação para coloração de 
Tabela 2 - Número de bandas polimórficas geradas pelos 28 primers RAPD selecionados e utilizados nos 116 acessos de açaizeiro.

\begin{tabular}{|c|c|c|}
\hline $\mathrm{N}^{\mathrm{o}}$ & Primer & $\mathrm{N}^{\mathrm{o}}$ de bandas polimórficas \\
\hline 1 & OPAR-11 & 10 \\
\hline 2 & OPAZ-03 & 14 \\
\hline 3 & OPAZ-11 & 13 \\
\hline 4 & OPB-01 & 05 \\
\hline 5 & OPB-02 & 08 \\
\hline 6 & OPB-05 & 08 \\
\hline 7 & OPB-09 & 08 \\
\hline 8 & OPB-10 & 08 \\
\hline 9 & OPB-11 & 11 \\
\hline 10 & OPB-14 & 07 \\
\hline 11 & OPB-16 & 10 \\
\hline 12 & OPB-18 & 11 \\
\hline 13 & OPBA-01 & 07 \\
\hline 14 & OPBA-02 & 08 \\
\hline 15 & OPBA-03 & 06 \\
\hline 16 & OPBA-04 & 12 \\
\hline 17 & OPBA-05 & 11 \\
\hline 18 & OPBA-06 & 12 \\
\hline 19 & OPBA-07 & 09 \\
\hline 20 & OPBA-08 & 09 \\
\hline 21 & OPBA-09 & 06 \\
\hline 22 & OPBA-10 & 07 \\
\hline 23 & OPL-01 & 11 \\
\hline 24 & OPL-07 & 10 \\
\hline 25 & OPL-15 & 08 \\
\hline 26 & OPM-04 & 15 \\
\hline 27 & OPM-11 & 08 \\
\hline 28 & OPS-19 & 11 \\
\hline Total & - & 263 \\
\hline
\end{tabular}

frutos maduros, respectivamente. Esses autores utilizaram marcadores RAPD e detectaram similaridades variando de 0,19 a 0,64 e de 0,16 a 0,66 , respectivamente, o que confirma a existência de grande diversidade genética entre os acessos dessa coleção. Em outras palmeiras perenes tropicais foram detectadas dissimilaridades de magnitudes próximas $(0,03$ a 0,71$)$ com o uso de marcadores RAPD
(HAYATI et al., 2004; MORETZSOHN et al., 2002). Com base nesses resultados, pode-se sugerir que coletas de açaizeiro devam ser direcionadas para populações naturais, pois há fortes indícios de que indivíduos de pomares caseiros, especialmente de localidades próximas, possam ser oriundos de frutos coletados de uma mesma planta superior e, portanto, tenham maior similaridade genética. 


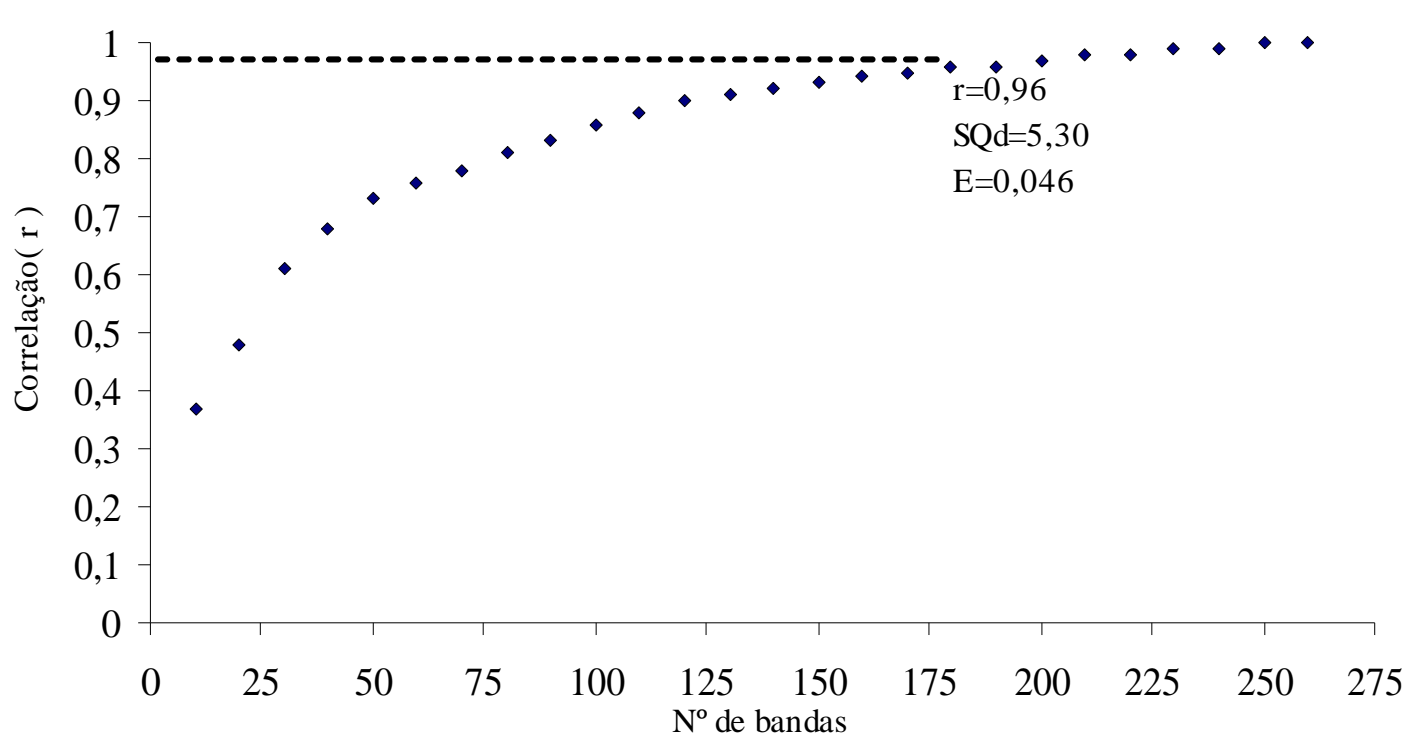

Figura 1 - Estimativas das correlações entre as dissimilaridades obtidas pela análise bootstrap para números crescentes de marcadores RAPD polimórficos na obtenção do número ideal de bandas entre os 116 acessos de açaizeiro estudados.

$\mathrm{Na}$ figura 2, encontra-se a distribuição da diversidade genética entre os acessos estudados. Verificase que dos 6.670 pares formados, 34,5\% ficaram incluídos no intervalo de classe de dissimilaridades de 0,37 a 0,42 , cujo ponto médio apresentou valor de 0,39 . Outra observação relevante é que menos de $1 \%$ dos pares ficaram distribuídos nas classes das extremidades e que a maioria deles $(83,7 \%)$ apresentou dissimilaridades variando de 0,31 a 0,53 , o que demonstra um padrão de distribuição contínuo. Tais resultados reforçam, mais uma vez, que os acessos dessa coleção possuem ampla diversidade genética e que a amostra do germoplasma analisado deve representar a variabilidade existente nessa coleção. Também, destaca o estuário amazônico como centro de diversidade genética dessa espécie, pois os acessos estudados são oriundos de coletas realizadas nesse local, onde os açaizeiros apresentam variações bem acentuadas para características morfológicas e de produção de frutos (OLIVEIRA et al., 1998), inclusive os aqui analisados (OLIVEIRA, 2005).

Com base no ponto de corte correspondente à dissimilaridade genética média $\left(d g_{m}=0,40\right)$, o dendrograma gerado permitiu a separação dos acessos em oito grupos (Figura 3), cujo agrupamento foi capaz de representar com alta confiança a matriz de dissimilaridades $(\mathrm{r}=0,81, \mathrm{P} \leq$
0,0001). Os quatro primeiros grupos foram constituídos por poucos acessos (o $1^{\circ}$ e o $2^{\circ}$ por um acesso e o $3^{\circ}$ e o $4^{\circ}$ por dois acessos), sendo eles: 14, 34, 100, 99, 82 e 81, considerados como os mais divergentes. Tais acessos podem ser indicados para compor coleções nucleares e para programas de melhoramento dessa palmeira. No caso dos dois acessos híbridos (115 e 116), estes ficaram contidos no $5^{\circ}$ grupo, onde se concentrou a maioria dos acessos do Maranhão e alguns do Pará, por apresentarem fortes semelhanças genéticas com acessos coletados em Cametá, PA (111, 112 e 114). Costa et al. (2001, 2004) também obtiveram a formação de cinco e dois grupos, respectivamente, quando analisaram indivíduos dessa mesma coleção, dando a idéia de que a diversidade genética esteja distribuída dentro de poucos agrupamentos. O mesmo fato foi registrado por Sawazaki et al. (1998) ao estudarem vários ecotipos de espécies pertencentes ao gênero Euterpe, incluindo o açaizeiro, o híbrido interespecífico entre E. edulis x $E$. oleracea e seu recíproco, o que permite assumir um padrão de distribuição típico de espécies alógamas e de parentesco próximo.

No caso das baixas dissimilaridades detectadas entre alguns acessos da mesma população (Breves, PA e de Macapá, AP), acredita-se que sejam decorrentes de 
cruzamentos entre indivíduos aparentados ou de autofecundações (SOUZA, 2002). Pois, populações dessas localidades têm sofrido forte redução de seus tamanhos, em conseqüência da exploração de palmito responsável pela eliminação de milhares de indivíduos. Nos acessos do Maranhão, as pequenas magnitudes podem estar relacionadas a vários fatores, como: a ocorrência de autofecundação; irregularidade da floração entre touceiras, ocasionando alta proporção de pólen de poucas plantas; e fluxo gênico à curta distância.

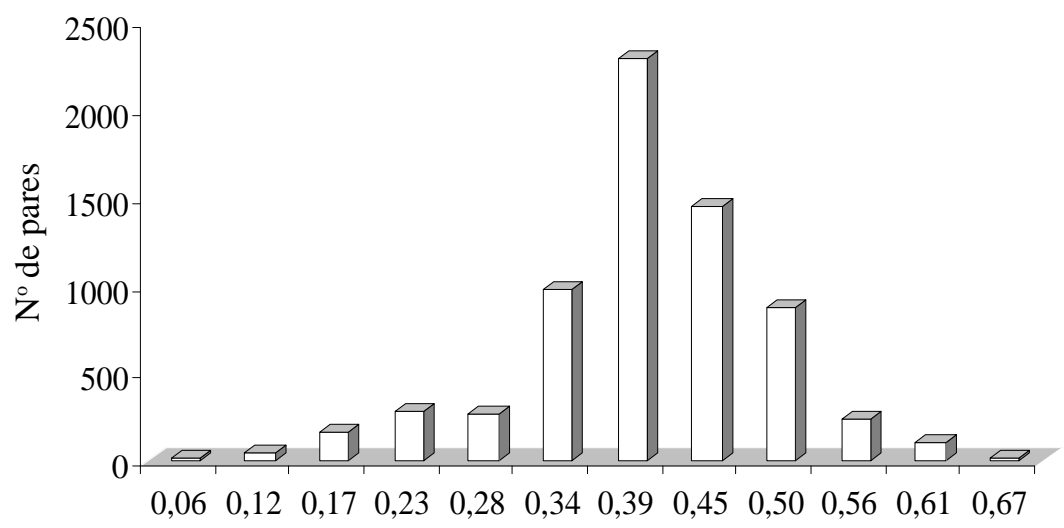

Classes de dis similaridades

Figura 2 - Distribuição de frequiência das estimativas de dissimilaridades genéticas, obtidas pelo complemento aritmético do coeficiente de Dice, com base nas 263 bandas polimórficas de RAPD geradas pelos 116 acessos de açaizeiro.

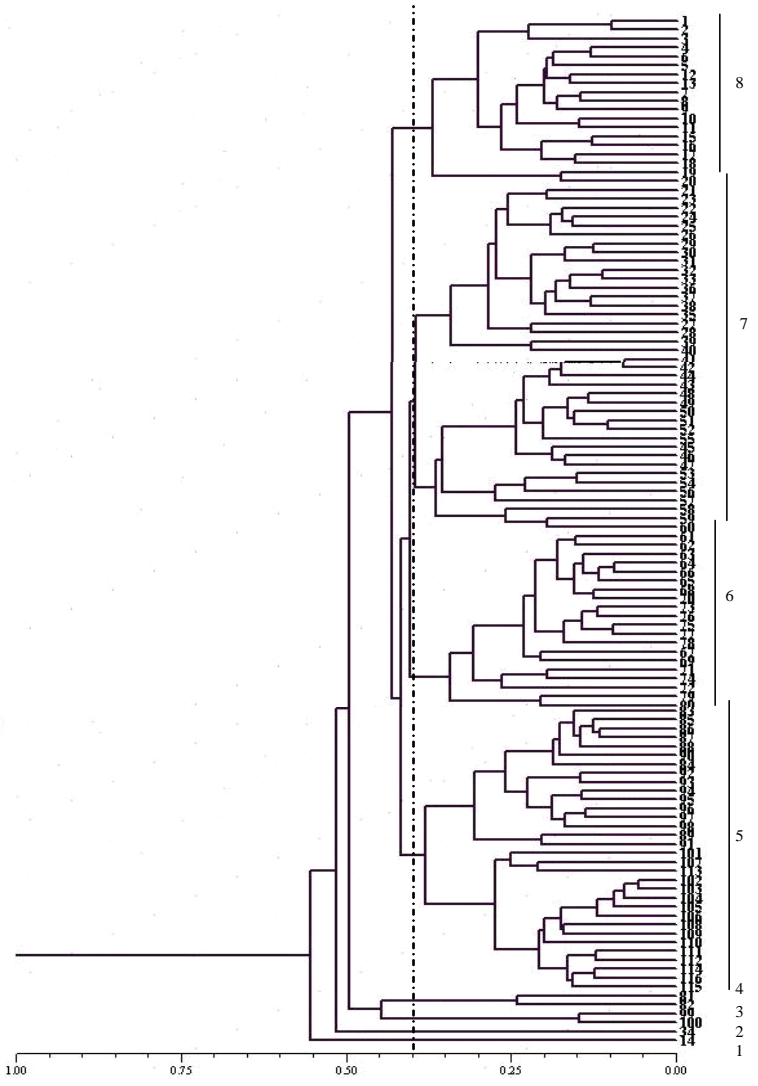

Figura 3 - Dendrograma gerado pelo método UPGMA pelas dissimilaridades genéticas, baseadas no complemento aritmético do coeficiente de Dice, com 263 bandas polimórficas de RAPD nos 116 acessos de açaizeiro. $d g_{m}=0,40$ 


\section{CONCLUSÕES}

Os acessos de açaizeiro da coleção da Embrapa Amazônia Oriental apresentam ampla diversidade genética detectada por marcadores RAPD e devem ser mantidos em bom estado de conservação para que sejam úteis na formação de coleções nucleares e em programas de melhoramento genético. Tais marcadores são eficientes na caracterização da diversidade genética interlocos desses acessos, permitindo a distinção dos mais similares e mais divergentes.

Os quatro acessos mais divergentes devem ser utilizados em programas de melhoramento genético dessa palmeira, principalmente na obtenção de híbridos.

O número de bandas polimórficas utilizadas neste estudo para a quantificação da diversidade genética foi bem acima do número ideal (180 bandas) pela análise bootstrap. Logo, as estimativas da diversidade genética entre os acessos estudados apresentam excelente precisão.

\section{REFERÊNCIAS BIBLIOGRÁFICAS}

CAVALCANTE, P. Frutas comestíveis da Amazônia. Belém, PA: CEJUP, 1991. $271 \mathrm{p}$.

COLOMBO, C.; SECOND, G.; CHARRIER, A. Diversity within American cassava germplasm based on RAPD markers. Genetics and Molecular Biology, Ribeirão Preto, v. 23, n. 1, p. 189-199, 2000.

COSTA, M. R.; OLIVEIRA, M. do S. P.; MOURA, E. F. Variabilidade genética em açaizeiro (Euterpe oleracea Mart.). Biotecnologia Ciência \& Desenvolvimento, Brasília, v. 21, p. 46-50, jul./ago. 2001.

COSTA, M. R.; OLIVEIRA, M. do S. P.; OHAZE, M. M. M. Divergência genética no açaizeiro com base em marcadores RAPD. Revista de Ciências Agrárias, Belém, n. 41, p. 8995, jan./jun. 2004

CRUZ, C. D.; SCHUSTER, I. GQMOL - aplicativo computacional para análise de dados moleculares e de suas associações com caracteres quantitativos. Versão 2.1. Viçosa: UFV, 2004.

FALEIRO, F. G.; LOPES, U. V.; YAMADA, M. M.; PIRES, J. L.; BAHIA, R. C. S.; SANTOS, R. C.; GOMES, L. M. C.; ARAÚJO, I. S.; FALEIRO, A. S. G.; GRAMACHO, K. P.; MELO, G. R. P.; MONTEIRO, W. R.; VALE, R. R. Caracterização de variedades clonais de Theobroma cacao
L com base em marcadores RAPD, AFLP e microssatélites. Agrotrópica, Bahia, v. 13, n. 2, p. 79-86, 2001.

FERREIRA, M. E.; GRATTAPAGLIA, D. Introdução ao uso de marcadores moleculares em análise genética. Brasília, DF: Embrapa/CENARGEN, 1998. 220 p.

HAYATI, A.; WICKNESWARI, R.; MAIZURA, I.; RAJANAIDU, N. Genetic diversity of oil palm (Elaeis guineensis Jacq.) germoplasm collections from Africa: implications for improvement and conservation of genetic resoucers. Theoretical Applied Genetic, Berlin, v. 108, n. 7, p. 1274-1284, May 2004.

KRUSKAL, J. B. Multidimensional scaling by optimizing goodness of fit to a no metric hypothesis. Psychometrika, Williamsburg, v. 29, n. 1, p. 1-27, 1964.

LIMA, R. R.; COSTA, J. P. C. da. Coleta de plantas de cultura pré-colombiana na Amazônia Brasileira: I. metodologia e expedições realizadas para a coleta de germoplasma. Belém: Embrapa; CPATU, 1997. 148 p. (Documentos, 99).

LLERAS, E.; GIACOMETTI, D. C.; CORADIN, L. Áreas críticas de distribución de palmas de las Americas para coleta, evaluación y conservación. In: INFORME DE LA REUNION DE CONSULTA SOBRE PALMERAS POCO UTILIZADAS DE AMERICA TROPICAL, 1983, San Jose. Anales... San Jose: CATIE/FAO, 1983. p. 67-81.

MANLY, B. F. J. Randomization, bootstrap and Monte Carlo methods in Biology. London: Chapman \& Hall, 1997.

MARQUES, J. R. B.; FALEIRO, F. G.; ARAÚJO, I. S.; ANHERT, D. Diversidade genética entre clones de seringueira das séries SIAL e Fx com base em marcadores RAPD. Agrotrópica, Bahia, v. 14, n. 3, p. 159-164, 2002.

MILACH, S. C. K. Principais tipos de marcadores moleculares e suas características. In: Marcadores moleculares em plantas. Porto Alegre: UFRGS, 1998. p. 17-28.

MORETZSOHN, M. C.; FERREIRA, M. A.; AMARAL, Z. P. S.; COELHO, P. J. A.; GRATTAPAGLIA, D.; FERREIRA, M. E. Genetic diversity of Brazilian oil palm (Elaeis oleifera H.B.K.) germplasm collected in the Amazon Forest. Euphytica, Wageningen, v. 124, n. 1, p. 35-45, 2002. 
NIENHUIS, J.; TIVANG, J.; SCKROCH, P.; SANTOS, J. B. dos. Genetic relations among cultivars and lines of lima bean (Phaseolus lunatus L.) as measured by RAPD marker. Journal of American Society for Horticultural Science, Alexandria, v. 120, n. 2, p. 300-306, Mar. 1995.

OLIVEIRA, M. do S. P. de. Aspectos da biologia floral do açaizeiro nas condições de Belém, PA. Belém, PA: Embrapa Amazônia Oriental. 2002. 19 p. (Boletim de Pesquisa, 8).

OLIVEIRA, M. do S. P. de. Caracterização molecular e morfo-agronômica de germoplasma de açaizeiro. 2005. 171 p. Tese (Doutorado em Genética e Melhoramento de Plantas) - Universidade Federal de Lavras, Lavras, 2005.

OLIVEIRA, M. do S. P. de; CARVALHO, J. E. U. de; NASCIMENTO, W. M. O. do. Açaí (Euterpe oleracea Mart.). Jaboticabal: Funep, 2000. 52 p. (Frutas nativas, 7).

OLIVEIRA, M. do S. P de; LEMOS, M. A.; SANTOS, E. O. dos; SANTOS, V. F. dos. Variação fenotípica em acessos de açaizeiro (Euterpe oleracea Mart.) para caracteres relacionados à produção de frutos. Belém, PA: EmbrapaCPATU, 1998. 23 p. (Boletim de pequisa, 209).

REIF, J. C.; MELCHONGER, A. E.; FRISCH, M. Genetical and mathematical properties of similarity and dissimilarity coefficients applied in plant breeding and seed bank management. Crop Science, Madison, v. 45, n. 1, p. 1-7, Jan./Feb. 2005.

RODRIGUES, D.; ASTOLFI FILHO, S.; CLEMENT, C. R Molecular marker-mediated validation of morphologically defined landraces of pejibaye (Bactris gasipaes) and their phylogenetic relationships. Genetic Resources and Crop Evolution, Dordrecht, v. 51, p. 871-882, 2004.
ROHLF, F. J. Numerical taxonomy and multivariate analysis system. Version 2.1. New York: Exeter Software, 2000. 38 p.

SAWAZAKI, H. E.; BOVI, M. L. A.; SODEK, L.; COLOMBO, C. A. Diversidade genética em palmeiras através de isoenzimas e RAPD. Revista Brasileira de Biologia, Rio de Janeiro, v. 58, n. 4, p. 681-691, 1998.

SOUSA, N. R.; RODRIGUES, D. P.; CLEMENT, C. R.; NAGAO, E. O.; ASTOLFI-FILHO, S. Discriminação de raças primitivas de pupunha (Bactris gasipaes) na Amazônia brasileira por meio de marcadores moleculares (RAPDS). Acta Amazônica, Manaus, v. 31, n. 4, p. 539545,2001

SOUZA, P. C. A. de. Aspectos ecológicos e genéticos de uma população natural de Euterpe oleracea Mart. no estuário amazônico. 2002. 60 f. Dissertação (Mestrado em Recursos Florestais) - Escola Superior de Agricultura "Luiz de Queiroz”, Piracicaba, 2002.

VICENTE, M. C. de; GUZMÁN, F. A.; ENGELS, J.; RAMANATHA-RAO, V. Genetic characterization and its use in decision making for the conservation of crop germplasm. In: THE ROLE OF BIOTECHNOLOGY, 2005, Turin. Proccedings... Turin: [s.n.], 2005. p. 121128.

YAMADA, M. M.; FALEIRO, F. G.; LOPES, U. V.; DANTAS NETO, A.; PIRES, J. L.; FLORES, A. B.; FALEIRO, A. S. G.; BAHIA, R. C. S. Diversidade genética de acessos de cacaueiro da série CEPEC por meio de marcadores RAPD. Agrotrópica, Bahia, v. 14, n. 3, p. 137-140, 2002. 